\title{
Analysis of the macrostructure of the fuel spray atomized with marine engine injector
}

\begin{abstract}
One of the main problem influencing the combustion process in the cylinder of the marine engine is an fuel spray phenomena. The parameters describing the shape of the fuel spray are named macro parameters. This article presents the research results of the macrostructure parameters of the fuel spray atomized with the marine engine injector. The research were carried out by optical visualization measurement method of Mie scattering. The diameter of nozzle injector was $0.375 \mathrm{~mm}$ and L/D coefficient 8.3. In these research were considered different parameters of injection opening pressures and backpressures in the constant volume chamber. Generally conlusions are: the opening pressure influence on maximum spray tip penetration, spray cone angle and influence on speed of the injected fuel. The increase of backpressure into the constant volume chamber causes the reduction of spray tip penetration and the increase of the spray cone angle.
\end{abstract}

Key words: marine diesel engine, marine fuel injector, spray tip penetration, spray cone angle, opening pressure, backpressure

\section{Introduction}

Diesel engines are the main type of propulsion of marine vessels. Typically, there are low-speed two-stroke diesel engines and medium-speed four strokes. Burning diesel oil by marine engines effects the emission of toxic compounds into the atmosphere. The amount of toxic compounds in exhaust gas of marine diesel engines are regulated by International Maritime Organization (IMO) [1]. Reduction of emission of toxic compounds by marine diesel engines is one of the most important aspects in nowadays diesel engines researches and engineers. The maximum engine efficiency and low emission toxic compounds are main aim during at the design stage of marine diesel engines.

The process of combustion in a marine diesel engine cylinders are mainly determined by fuel injection process [2].

High pressure of injection and controlled fuel delivery are the advantages of the common rail system. For this purpose, the common rail injection system is used in marine diesel engines. The first Common Rail system in marine, medium speed, 4 stroke engine was installed in 2001. High injection pressure are preferred for reduce excessive emission of toxic compounds [3]. Therefore, it is important to researches conducted the studies of influence injection pressures on the fuel spray and combustion process into cylinders. The combustion process in the cylinder of the marine diesel engines is diversified. The process of fuel delivery to cylinder, fuel injection and fuel combustion should be analyzed separately. Furthermore, the research of the phenomenon occurring in the combustion chamber are fast changing. The subject of the injection fuel process into the real operating marine engines may belong impossible or very expensive. There is alternative such is: the constant volume chamber - simulating conditions of combustion chamber marine diesel engines, optical methods - measurements of the injection process into combustion chamber [4].

Fuel delivered by marine engine injector to cylinder is atomized, evaporated and mixed with air. Injected fuel had a shape of a cone with a spherical forehead described with macro parameters: tip penetration and spray cone angle. Tip penetration and spray cone angle are present fuel droplets ability to penetrate in gaseous environment in combustion chamber. Over the years, many researches have performed a lot of studies in order to research the spray tip penetration and spray cone angle. In the' $80 \mathrm{~s}$ and ' 90 s the pioneering works about research of macro parameters were presented by Hiroyasu \&Arai [5] and Naber \&Siebers [6]. Author's proposed the diesel fuel atomization models which assumes that spray tip penetration is linear proportional to the time only at the early injection period. After this time, the spray tip penetration evaluated with proportional rate to square root of time. The Hiroyasu \&Arai or Naber \&Siebers fuel atomization model are basis for researches to development innovative models. Macro parameters are mainly depend for geometrical parameters of fuel injection system and environmental conditions in cylinder. Generally, the geometrical and operating parameters are [7]: diameter of nozzle, L/D ratio, energizing time of fuel injection, injection pressure and others. The parameters of environmental conditions are $[8,9]$ : air swirls movement, backpressure or temperature of fuel and air.

Payri R. et al. $[10,11]$ have performed researches on the influence of orifice geometry on the flow at the nozzle exit and its effect on the macro parameters. The conclusion is that cylindrical nozzle provided the highest values of liquid spray tip penetration at low injection pressures in range 30 and $80 \mathrm{MPa}$. The change temperature during of combustion process in cylinder causes changes of the fuel density and viscosity. Such a phenomenon caused the poor atomization [8] and vaporization $[12,13]$. In the literature, there are many studies concerning the macro parameters of the fuel injection depending on injection pressures and backpressures. Du W. et al. [14] presented the influence injection pressure for behaviors of liquid phase spray and vapor spray. The measurement were performed in the constant volume chamber. High speed camera and Schlieren visualization set-up are used to registration results. Their test results presented influence injection pressure for spray penetration rate and the effect of pressure on general development of spray cone angle is negligible.

Presented studies of the macro parameters of diesel fuel spray are presented for fuel injector of the lower of geomet- 
rical parameters compared the geometrical parameters of marine diesel engines. Therefore, study of diesel spray parameters of marine engines is needed.

The paper presents results of macroscopic parameters of fuel spray for the chosen backpressure conditions and chosen opening pressures of marine fuel injector.

\section{Laboratory setup}

Laboratory studies presented in this article were carried out in Warsaw University of Technology. The chosen parameters correspond with the parameters observed in marine engines. The nozzle diameter was of $0.375 \mathrm{~mm}$ and L/D coefficient 8.3 respectively. The all measurements of fuel spray were conducted of the ambient temperature. The temporary evolution sprays parameters was observed in the constant volume chamber (Fig. 1, Table 1). The environmental conditions in constant volume chamber was backpressure 3.2 $\mathrm{MPa}$ and 4.3 $\mathrm{MPa}$. Those backpressures were defined adequately operation marine diesel engine with to half- and full- load engine operation.

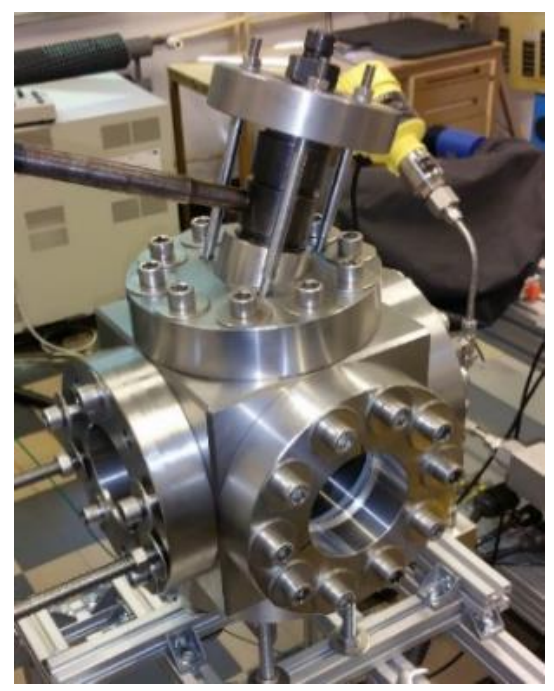

Fig. 1 Constant volume chamber

Marine fuel injector was installed at the top in the constant volume chamber (Fig. 2). This configuration allow to observation of single jet evolution fuel sprays. The observation area of fuel sprays equals up to $100 \mathrm{~mm}$ (half of the cylinder bore).

Table 1 The parameters of the constant volume chamber

\begin{tabular}{|l|c|c|}
\hline Dimensions & $200 \times 200$ & $\mathrm{~mm}$ \\
\hline Optical view & 100 & $\mathrm{~mm}$ \\
\hline Backpressures & $3.2,4.3$ & $\mathrm{MPa}$ \\
\hline Measurement space & nitrogen & - \\
\hline Number observation windows & 3 (all 4) & - \\
\hline
\end{tabular}

Fuel injector used in this study is the part of laboratory marine diesel engine Sulzer 3 Al 25/30. The injector is a conventional pressure opened diesel injector equipped with UPS (Unit pump system). Fuel injector supplies diesel oil of $300 \mathrm{~K}$ temperature. The tested spray of diesel was made by one active injector nozzle. Others injector nozzle was plugged. In the presents study the injector nozzle with
$0.375 \mathrm{~mm}$ diameter and $8.3 \mathrm{~L} / \mathrm{D}$ coefficient was investigated. The fuel was supplied to the injector by a high pressure common rail system equipped with fast-acting electromagnetic valve. The pressure behind the injector was measured by Kistler type 4067E piezorezistive pressure sensor. The specifications of the pressure sensor was showed in [15]. The fuel pressure in system equals $50 \mathrm{MPa}$. The different opening pressure of marine fuel injector was considered in this study. The opening pressure range was $15 \mathrm{MPa}, 25$ $\mathrm{MPa}$ and $35 \mathrm{MPa}$, respectively. Measured diesel oil viscosity and density at $40^{\circ} \mathrm{C}$ was of $2.35 \mathrm{mPa} \cdot \mathrm{s}$ and $816.1 \mathrm{~kg} / \mathrm{m}^{3}$ respectively. The temperature of test was $300 \mathrm{~K}$. In this work, the optical Mie scattering method was used [4, 16]. The experimental setup system is shown in Fig. 2.

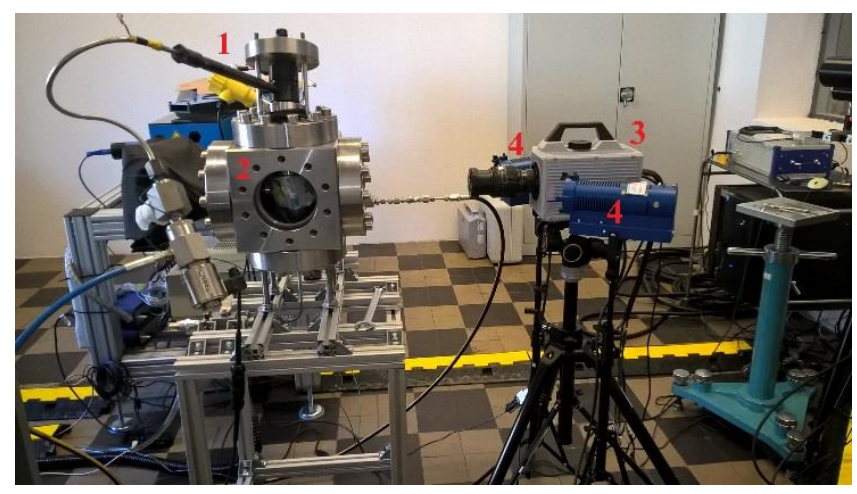

Fig. 2 The experimental setup system: 1 - marine engine injector, 2 constant volume chamber, 3 - Photron SA1.1 high-speed camera, 4 - 2x halogen lights $0.5 \mathrm{~kW}$

In Mie scattering method, important aspect is adequate lighting of sheet spray. On the based measurements requirements of macro spray parameters were chosen integral illumination of the spray.
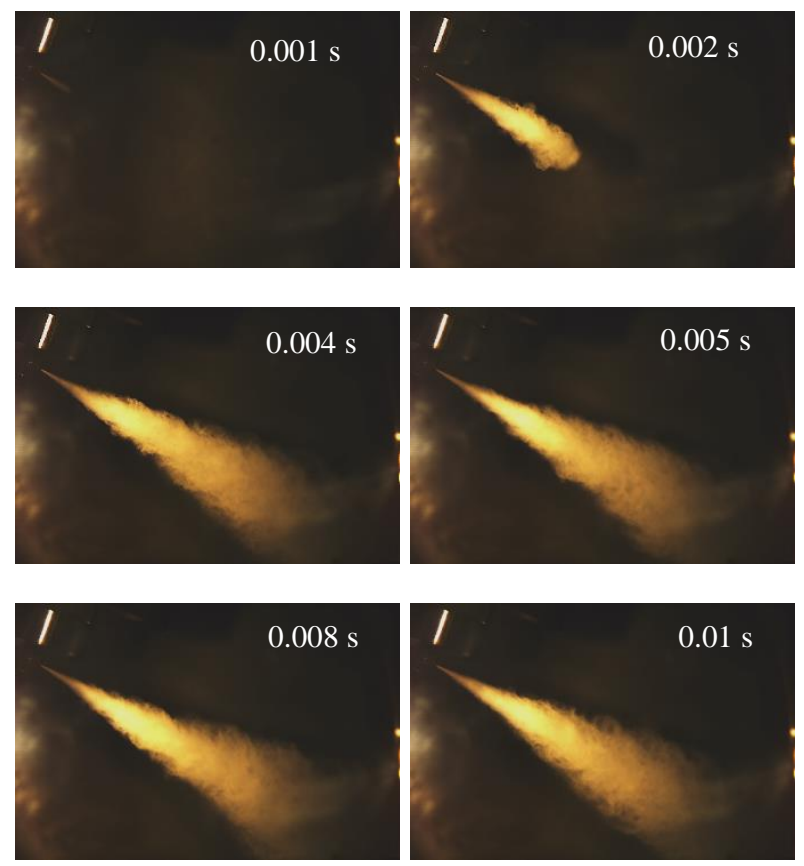

Fig. 3. The chosen pictures of diesel spray in time - the nozzle diameter $0.375 \mathrm{~mm}, \mathrm{~L} / \mathrm{D} 8.3$, opening pressure $25 \mathrm{MPa}$ and backpressure $4.3 \mathrm{MPa}$ 
Two halogen lights were used. In the determination of global spray parameters, the integral type of illumination is very well. The diesel fuel sprays were observed by a Photron SA1.1 high speed camera. The images were recorded at a frequency of $40 \mathrm{kHz}$ and resolution of the recorded images was $512 \times 256$ pixels.

The measurement was repeated three times at each point. In single measurement was generated about 500 images, where about 250 images has been used to photo processing. The Fig. 3 presented chosen pictures generated from the marine fuel injector in the constant volume chamber. Selected photos contained the range injection process from the beginning of the injection to the complete development of the spray. Prior to the generated of the macro parameters of the diesel spray, images had to be prepared. The first step of photo processing was scaling from pixels to millimeters. At the same time, it had to be verified or improved of the nozzle position in the photo. One pixel is equal $0.13 \mathrm{~mm}$ in this photo processing. The next step was used spray isolator function to separate the spray from the ambient and to eliminate reflections and image noises within spray. The example of images processing effect is presented in Fig. 4. The mentioned photo processing were carried out by DaVis v8.4 software.

\section{Results and discussion}

The Fig. 4 presents example results of macro parameters of the tested diesel spray. The spray tip penetration (STP) is defined as a maximum distance of fuel spray from the hole nozzle outlet [17]. According to the presented results in Fig. 4 , spray cone angle is defined by two lines on the boundaries on the left and right sides which made cone.

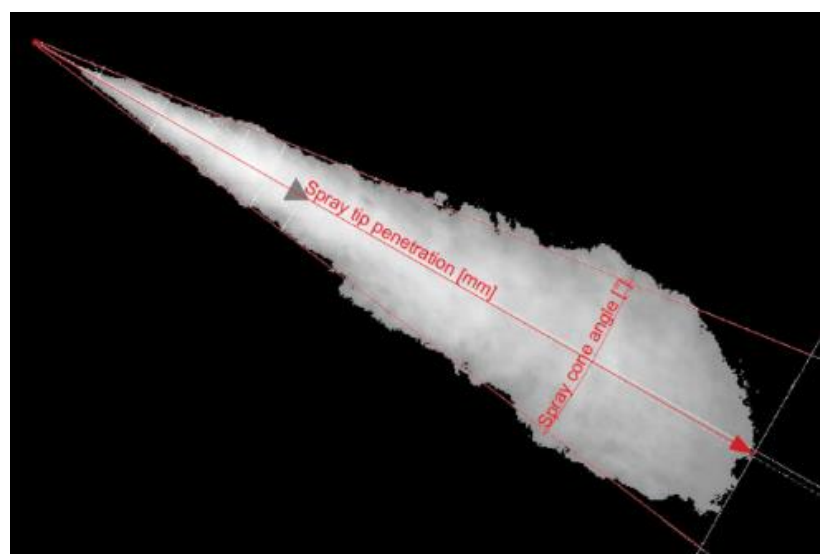

Fig. 4 Macro spray parameters

\subsection{Spray tip}

Figure 5 presents STP for opening pressures of 15, 25 and $35 \mathrm{MPa}$ for two backpressures in the constant volume chamber of 3.2 $\mathrm{MPa}$ and 4.3 $\mathrm{MPa}$ in non-evaporating conditions. The test results are the arithmetic average of the three repetitions of the measurement. All presented cases are similar to studies by Hiroyasu\&Arai [5]. The spray tip penetration is presented in range to the time of $0.01 \mathrm{~s}$, because after $0.008 \mathrm{~s}$ it achieves the constant level of maximum penetration. The maximum spray penetration is range 70-100 $\mathrm{mm}$ for all the considered opening pressures, backpressures. In the early stage of diesel fuel injection
STP increases with time, until achieving a stabilization stage. All the considered curves in time of STP may be defined in two stages: the initial increase stage and the steady development stage. During the steady development stage STP does not increase but only oscillates about its average range. According to results presented in [18], when the distance of the spray tip penetration increases, droplets diameters decrease. This is caused by primary and secondary breakup of droplets of fuel spray and aerodynamics resistances in the constant volume chamber. The steady development stage of STP presents of maximum of breakup droplets. This phenomena caused that STP did not grow up. The start time of stabilization stage of STP was presented by the vertical lines on the Fig. 5 .
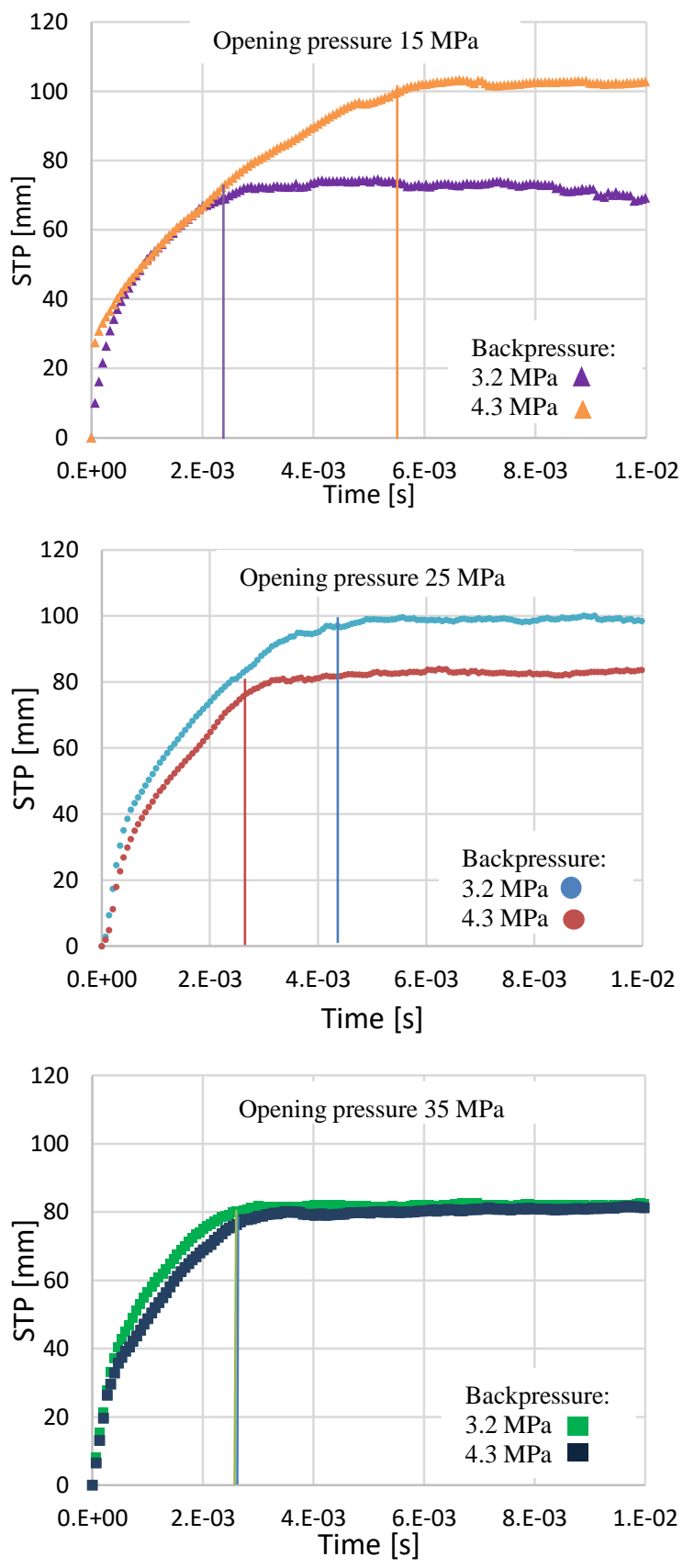

Fig. 5. Spray tip penetration for $0.375 \mathrm{~mm}$ diameter nozzle, opening pressures: a. $15 \mathrm{MPa}$, b. $25 \mathrm{MPa}$, c. $35 \mathrm{MPa}$, backpressures: $3.2 \mathrm{MPa}$ and 4.3 $\mathrm{MPa}$ 
The initial penetration STP is determined by the injection dynamics, instead of the ambient conditions [19]. This can be see on the Fig. 5 where the increase of backpressure has little effect on STP at the initial increase stage where the diesel spray is dense. This may be due to the much higher injection pressure compared to the backpressure in constant volume chamber. Higher opening pressure can be increased kinetic energy of diesel fuel spray. The STP of fuel diesel has larger kinetic energy to penetrate and results in a faster achieving stabilization stage and highest of STP.
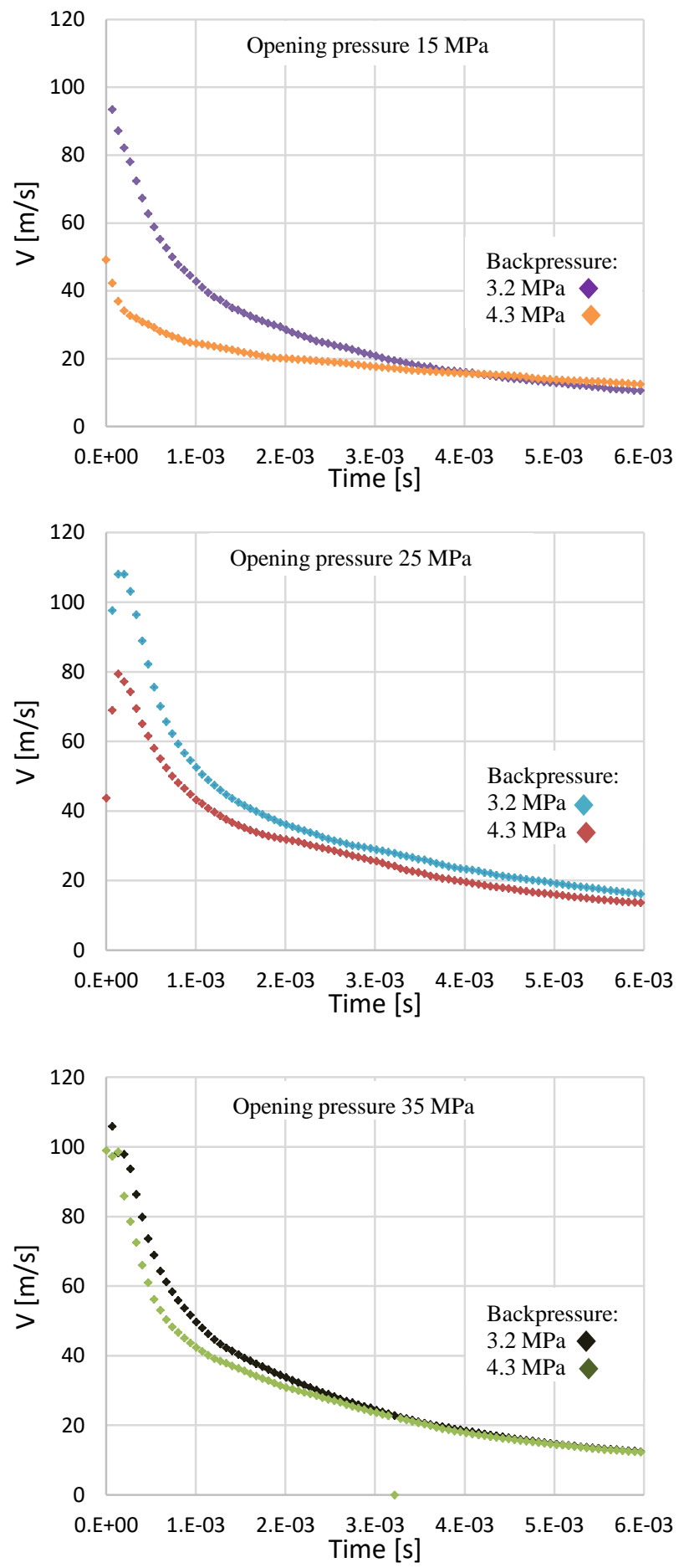

Fig. 6. Speed of STP: different opening pressures and backpressures: a. 3.2 $\mathrm{MPa}$ and b. 4.3 $\mathrm{MPa}$
After initial propagation in time of STP, the spray becomes thin and the effect of aerodynamic force gradually increases. The kinetic energy of diesel fuel spray was reduced. It can be explained that the droplets of fuel in STP were slowed by increases of aerodynamic resistances. The results presented on Fig. 5 is expected for opening pressure of $25 \mathrm{MPa}$. Increase of backpressure of $3.2 \mathrm{MPa}$ to $4.3 \mathrm{MPa}$ causes significant reducing of STP and reducing time of achieving of stabilization stage of STP for opening pressure of $25 \mathrm{MPa}$. For higher opening pressure (35 MPa) the change is not observed. The opposite situation was observed for opening pressure $15 \mathrm{MPa}$ : higher backpressure caused elongation in time achieving and increases the stabilization stage of STP.

On the other hand, opening pressure and backpressure have influenced the speed of STP in initial stage. On the Fig. 6 presents curves of speed V [m/s] of STP in time for considered opening pressures of marine diesel injector and backpressures in the constant volume chamber are presented. The increase of opening pressure was caused the increase of fuel injection speed at the initial stage of injection.

According to the results, for increase backpressure of 4.3 $\mathrm{MPa}$ there is observed reduction of initial speed of STP in comparison to backpressure of $3.2 \mathrm{MPa}$ for all considered opening pressures. The biggest influence of backpressure on initial speed of STP is for opening pressure of $15 \mathrm{MPa}$. For opening pressure $25 \mathrm{MPa}$ and $35 \mathrm{MPa}$ influence of backpressure caused small difference in initial speed of STP.

On the Fig. 7 presents averages STP of stabilization stages. Increase of opening pressures caused increases of STP for backpressure 3.2 MPa. Opening pressure of 25 MPa caused the increase of STP by approx $34 \%$ and opening pressure of $35 \mathrm{MPa}$ by approx $13 \%$ in compared to STP for lower opening pressure.

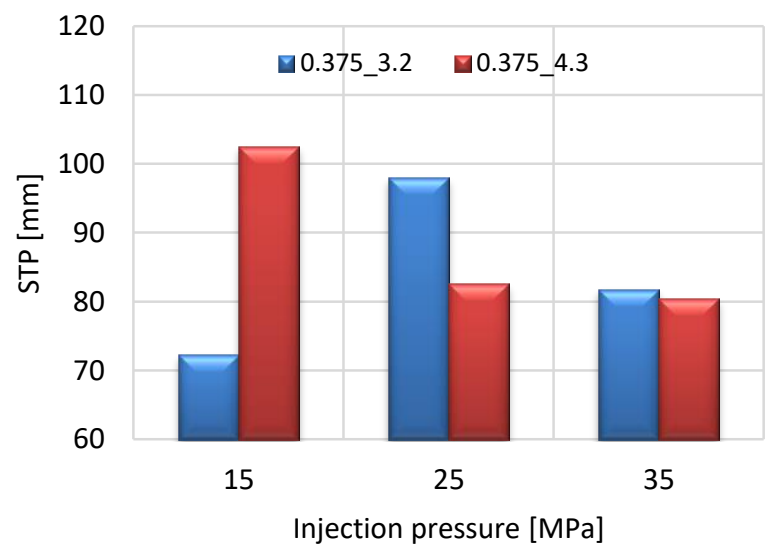

Fig. 7. The averages STP of stabilization stages for backpressures $3.2 \mathrm{MPa}$ and $4.3 \mathrm{MPa}$

According to results presents on Fig. 7, the STP decreases with increases of opening pressures, for backpressure of 4.3 MPa compared to backpressure of 3.2 MPa. For opening pressure of $15 \mathrm{MPa}$ the STP is the highest. The change of opening pressure from of $15 \mathrm{MPa}$ to $25 \mathrm{MPa}$ caused a reduction of STP of about $20 \%$. However, between the opening pressures of 25 and $35 \mathrm{MPa}, 2 \%$ difference of STP was observed. 
In conclusion, opening pressure has effect on STP of marine diesel engine injector. The course in time of STP is created by injection dynamics of STP and minimal effect of backpressure in constant volume chamber during initial stage. The backpressure in stabilization stage has the main influence on maximum STP.

\subsection{Spray cone angle}

Figure 8 presents the course of the spray cone angle (SCA) in time for opening pressures of 15,25 and $35 \mathrm{MPa}$ and backpressures of $3.2 \mathrm{MPa}$ and $4.3 \mathrm{MPa}$ in nonevaporating conditions.
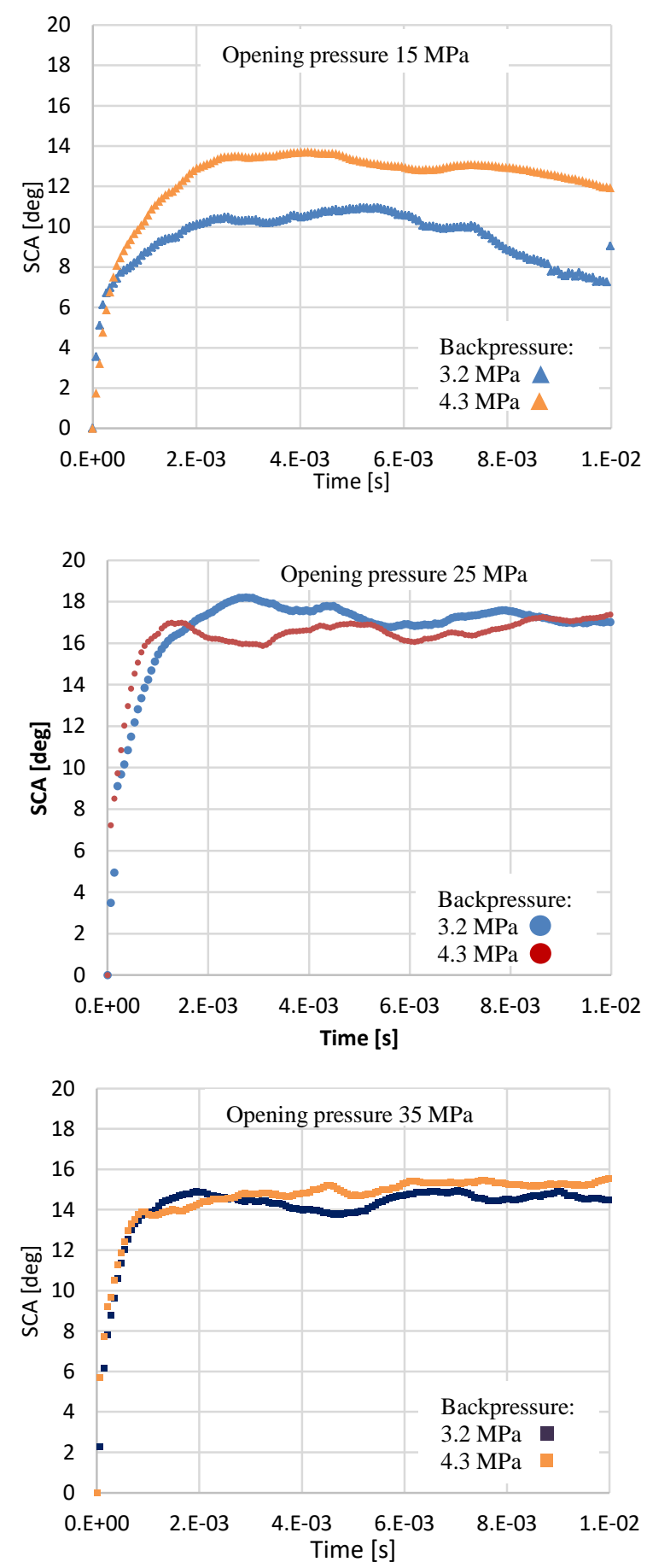

Fig. 8 Spray cone angle for $0.375 \mathrm{~mm}$ diameter nozzle, different opening pressures and backpressures: a. 3.2 $\mathrm{MPa}$ and b. $4.3 \mathrm{MPa}$
All the presented characteristics of SCA appeared the initial stage. This initial stage lasts approximately $0.001 \mathrm{~s}$ in each considered cases. During initial stage of SCA, the rate course of SCA is not the same. The rate of SCA depending on considered backpressure are a little differences for opening pressures of $15 \mathrm{MPa}$ and $35 \mathrm{MPa}$. For opening pressure of $25 \mathrm{MPa}$ increase rate of SCA for backpressure 4.3 MPa in compared backpressure $3.2 \mathrm{MPa}$ was observed. This phenomenon can be attributed to the ambient gas resistance generated in the constant volume chamber which influenced on the surface wave around the periphery of spray. The initial stage is followed by a period with relatively constant "quasi-steady" spray angle. The presented results are similar to [6]. The SCA during the initial transient stage can significantly exceed the quasi-steady angle or can remain on the same level. The SCA in quasi-steady spray angle for the marine diesel injector is $10^{\circ}$ to $18^{\circ}$.

Based on Fig. 9, for all considered backpressures, the SCA increases along with the increase in the opening pressure. This is consistent with the research results presented in [5]. In the presented research result the maximum SCA was achieved for opening pressure of $25 \mathrm{MPa}$ in both considered backpressures in the constant volume chamber.

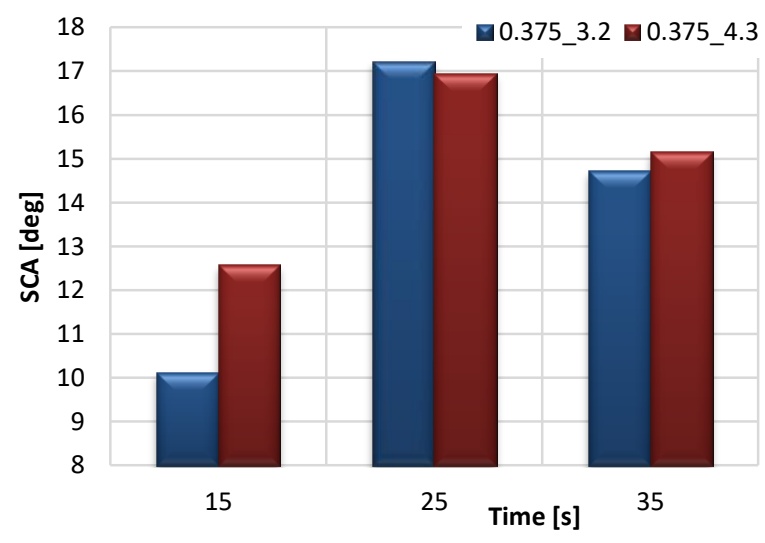

Fig. 9. Effect of injection pressure on maximum SCA for backpressures $3.2 \mathrm{MPa}$ and $4.3 \mathrm{MPa}$

Between opening pressures of $15 \mathrm{MPa}$ and $25 \mathrm{MPa}$, the biggest difference in SCA is observed. The mentioned difference of SCA is $4^{\circ}-7^{\circ}$ while between opening pressures of $25 \mathrm{MPa}$ and $35 \mathrm{MPa}$ difference is about $2^{\circ}$. This is due to the larger nozzle in marine diesel engines which changes the outlet flow pattern in compared small general diesel engines. In marine diesel engines with relatively big fuel nozzles, the fuel spray is along the axis of nozzle while in diesel engines fuel is spray divergently [20].

In case of the increase of backpressure from 3.2 MPa to $4.3 \mathrm{MPa}$ in the constant volume chamber, there are observed significant increases of SCA for of $15 \mathrm{MPa}$ opening pressure (Fig. 9). For other considered opening pressures, influence change backpressures on SCA is insignificant. Increasing opening pressure can change the kinetic energy of the fuel which causes friction between fuel and ambient gas resulting in breaking up. Therefore, increases of backpressure cause increases of SCA for marine engine injector. 


\section{Conclusions}

This paper presents tests of macro parameters of fuel diesel spray from a marine engine injector. According to presented research the following conclusions may be formulated:

- The opening pressure of marine engine injector influences the maximum spray tip penetration and the spray cone angle;

- The opening pressure of marine engine injector influences the initial speed of spray tip penetration. Together with the increasing of opening pressures of marine injector the initial speed of fuel spray also increases; During steady development stage of spray tip penetration, the influence of opening pressure can be neglected for higher opening pressures;
- Backpressures in constant volume chamber influence macro parameters of diesel fuel spray in steady development stage. The increase of backpressure in the constant volume chamber causes the reduction of speed of spray tip penetration, maximum of spray tip penetration and the spray cone angle.

\section{Acknowledgements}

The authors wish to thank DSc., DEng. Jerzy Kowalski - Gdańsk University of Technology, DEng. Łukasz Jan Kapusta and MEng. Piotr Jaworski - Warsaw University of Technology for the technical support and valuable remarks on the optical research of parameters of the fuel injection.

\section{Nomenclature}

STP Spray Tip Penetration
SCA Spray Cone Angle

[12] KAPUSTA, Ł.J, PIELECHA, I., WISŁOCKI, K., TEODORCZYK, A. Autoignition and combustion of n-hexane spray in subcritical and supercritical environments. $J$ Therm Anal Calorim. 2016, 123, 819-828. DOI: 10.1007/s10973015-4927-z

[13] PARK, S.H., KIM, H.J., LEE, C.S. Comparison of experimental and predicted atomization characteristics of highpressure diesel spray under various fuel and ambient temperature. J Mech Sci Technol. 2010, 24. DOI: 10.1007/ s12206-010-0417-1

[14] DU, W., LOU, J., YAN, Y. et al. Effects of injection pressure on diesel sprays in constant injection mass condition. Appl Therm Eng. 2017, 121, 234-241. DOI: 10.1016/ j.applthermaleng.2017.04.075

[15] LEWIŃSKA, J., KAPUSTA, Ł.J. Analysis of the microstructure of the fuel spray atomized by marine injector. Combustion Engines. 2017, 169, 120-124. DOI: 10.19206/ CE-2017-221

[16] ZIGAN, L., SCHMITZ, I., FLUGEL, A. et al. Structure of evaporating single- and multicomponent fuel sprays for 2 nd generation gasoline direct injection. Fuel. 2011, 90, 348363. DOI: $10.1016 /$ j.fuel.2010.08.001

[17] HEYWOOD, J.B. Internal Combustion Engine Fundementals. 1998, 21. DOI: 10987654

[18] YAO, C., GENG, P., YIN, Z. et al. Impacts of nozzle geometry on spray combustion of high pressure common rail injectors in a constant volume combustion chamber. Fuel. 2016, 179, 235-245. DOI: 10.1016/j.fuel.2016.03.097

[19] JING, D., ZHANG, F., LI, Y. et al. Experimental investigation on the macroscopic and microscopic spray characteristics of dieseline fuel. Fuel. 2017, 199, 478-487. DOI: 10.1016/j.fuel.2017.02.055

[20] YAN, F., DU, Y., WANG, L. et al. Effects of injection pressure on cavitation and spray in marine diesel engine. Int J Spray Combust Dyn. 2016, 1-13. DOI: 10.1177/ 1756827716672472

Grochowalska Joanna, MEng.- Faculty of Ocean Engineering and Ship Technology, Gdańsk University of Technology.

e-mail: joanna.lewinska@pg.edu.pl

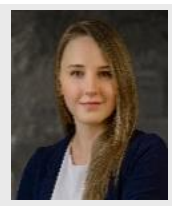

